Research Article

\title{
Vibration Reduction of the Nonlinearly Tufted Carpet Yarn by a Modified Sliding Mode Control Method
}

\author{
Shuang Huang $(\mathbb{D}$, Xin Wu, and Peixing Li $\mathbb{D}$ \\ Department of Mechanical and Automotive Engineering, Shanghai University of Engineering Science, Shanghai, China \\ Correspondence should be addressed to Shuang Huang; huangshuang1989@126.com
}

Received 14 December 2018; Revised 19 March 2019; Accepted 26 March 2019; Published 28 April 2019

Academic Editor: Brij N. Agrawal

Copyright (c) 2019 Shuang Huang et al. This is an open access article distributed under the Creative Commons Attribution License, which permits unrestricted use, distribution, and reproduction in any medium, provided the original work is properly cited.

\begin{abstract}
The yarn vibration causes the yarn tension value to fluctuate, causing a change in the amount of yarn feed, thus causing a deviation of the carpet pile height from the predetermined value. To solve this problem, the sliding mode control algorithm is used to design the sliding mode function and the sliding mode control law. And four variables in the yarn vibration system are controlled by the MATLAB software. For solving the chattering problem of the control law, the sliding mode control law is improved. The fuzzy sliding mode control algorithm based on the quasisliding mode is adopted. The results show that the sliding mode control algorithm is effective, but the sliding mode control force needs to be switched at high frequency and there is severe chattering. The fuzzy sliding mode control algorithm based on quasisliding mode is adopted to achieve better control effect with a smaller force. In addition, the control force does not have high-frequency switching, and the change is relatively stable, which reduces the chattering phenomenon of sliding mode control.
\end{abstract}

\section{Introduction}

The actuators in tufting carpet machine and the yarn coupling act together to implant the yarn into the base fabric, thereby forming a tufted carpet $[1,2]$. There are many evaluation indicators of carpet surface quality, such as appearance quality, pile density, carpet backing peeling strength, and color fastness. When consumers choose carpet, the most intuitive way is to see the appearance, including the evenness of carpet and carpet cleanliness. The height of carpet surface determines the evenness of the carpet surface. However, the yarn vibration causes the yarn tension value to fluctuate, causing a change in the amount of yarn fed, thus causing a deviation of the carpet pile height from the predetermined value. Therefore, it is necessary to control the vibration of yarn in a reasonable range.

To control the yarn vibration, a reasonable controller is needed. At present, there are many control methods for nonlinear systems, such as neural network control [3-5], sliding mode control [6-9], adaptive control [10,11], and so on. Among them, sliding mode control has many advantages, such as quick response, online monitoring, simple realization, and strong anti-interference ability. It is widely used in many practical engineering fields, such as trajectory tracking control of aircraft and robot and motor and electric power system control. For example, Liaw et al. [12] realized the missile guidance system control based on sliding mode variable structure control and effectively suppresses the jitter caused by the discontinuity of the system. Considering the influence of the rotational inertia, aerodynamic force, and gust interference on the cruise missile, Yeh et al. [13] used the four-element optimal integral sliding mode variable structure control and designed the optimal medium range guidance law. Dansoko et al. [14] proposed the discrete sliding mode variable structure control to adjust the frequency and voltage of the synchronous generator and improve the efficiency of energy production.

Sliding mode variable structure control is also widely used in nonlinear continuum vibration control. For example, Fung et al. [15] designed sliding mode control law with proportional compensator and integral compensator, which reduces the vibration of string and makes the 
system have a faster response speed. Based on the boundary control method combining fuzzy sliding mode control and fuzzy neural network control, Huang et al. [16] constructed the Lyapunov scalar function that describes the system energy and established the control law so that the total energy of the system decays to zero, so as to suppress the transverse vibration of the axially moving string. Yu et al. [17] adopted the sliding mode variable structure method to control the angular displacement of the tensioning arm in the flat belt driving system. The above research results are all aimed at the study of chord lines, beams, and other axis continuum. However, vibration control of carpet yarn harness for special materials is rarely reported. But the above research results can be used as a reference for studying yarn vibration control methods.

In this paper, based on the sliding mode control algorithm and fuzzy sliding mode control algorithm, the yarn vibration is controlled. The change of control force is stable by using fuzzy sliding mode control algorithm, which reduces the chattering phenomenon of sliding mode control.

\section{Effect of Yarn Vibration on the Carpet Pile Height}

The carpet pile height is the distance from the bottom cloth to the carpet face, as shown in Figure 1. In Figure 1, the pile height is $H \mathrm{~mm}$, the thickness of black cloth is $d \mathrm{~mm}$, and the distance between the pile loops is $a \mathrm{~mm}$. The yarn consumption that forms a pile loop is $L$.

$$
L=2(H+d)+a .
$$

Assuming the spindle speed is $n_{1} \mathrm{rpm}$, the speed of the servo motor controlled by jacquard rollers is $n_{2} \mathrm{rpm}$, and the jacquard roller radius is $r_{\mathrm{j}} \mathrm{mm}$. Now,

$$
L=2(H+d)+a=2 \pi r_{\mathrm{j}} \frac{n_{2}}{n_{1}} .
$$

In the tufting carpet machine, $a$ can be expressed as

$$
a=2 \pi r_{\mathrm{b}} \frac{n_{3}}{n_{1}},
$$

where $r_{\mathrm{b}}$ is the radius of spiny roll for feeding the black cloth $(\mathrm{mm})$ and $n_{3}$ is the speed of spiny roll for feeding the black cloth (rpm).

Taking the jacquard parts as the object of analysis, according to A. P. Minakov Euler tension formula [18], the output yarn tension $F_{1}$ of jacquard roller can be expressed as

$$
F_{1}=\left(F_{0}-m v^{2}\right) e^{\mu \alpha}+m v^{2},
$$

where $F_{0}$ is the input tension of jacquard parts, $m$ the yarn quality for unit length, $\mu$ is the friction factor of contact surface between yarn and jacquard wheel, $\alpha$ is wrap angle, and $v=2 \pi n_{2} r_{\mathrm{j}} / 60$ is the yarn speed.

According to equations (2)-(4), the relationship of tension and pile height is

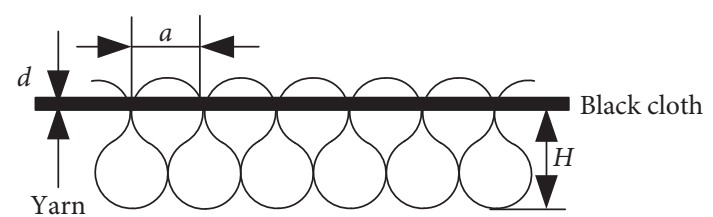

Figure 1: Schematic diagram of pile loop.

$$
\begin{gathered}
H=\frac{30 \sqrt{\left(F_{4}-F_{3} e^{\mu \alpha}\right) / m\left(1-e^{\mu \alpha}\right)}}{n_{1}}-\frac{1}{2} \\
\cdot a-d=\frac{30 \sqrt{\left(F_{4}-F_{3} e^{\mu \alpha}\right) / m\left(1-e^{\mu \alpha}\right)-\pi r_{\mathrm{b}} n_{3}}}{n_{1}}-d .
\end{gathered}
$$

Taking the DHGN801D-400 tufting carpet machine as an example, $\quad a=1 / 10 \mathrm{in}=2.54 \mathrm{~mm}, \quad \alpha=\pi / 2, \quad \mu=0.9$, $m=0.00023 \mathrm{~kg}, \quad n_{1}=600 \mathrm{rpm}, d=0.3 \mathrm{~mm}, \quad F_{1}=0.89 \mathrm{~N}$, $F_{0}=0.5 \mathrm{~N}$. According to equation (5), the carpet face can be calculated. According the literature [19], the transverse vibration equation of the yarn is as follows:

$$
\begin{aligned}
\dddot{q}+\left[\frac{E_{1}}{\eta_{2}}\left(1+\frac{E_{2}}{E_{1}}+\frac{\eta_{2}}{\eta_{3}}\right)+\frac{c}{\rho}\right] \dddot{q} \\
+\left\{\left[\frac{F}{A \rho}-v^{2}\right] \frac{\pi^{2}}{l^{2}}+\frac{E_{1} E_{2}}{\eta_{2} \eta_{3}}+\frac{c E_{1}}{\eta_{2} \rho}\left(1+\frac{E_{2}}{E_{1}}+\frac{\eta_{2}}{\eta_{3}}\right)\right\} \ddot{q} \\
+\left\{\left[\frac{F}{A \rho}-v^{2}\right] \frac{E_{1} \pi^{2}}{\eta_{2} l^{2}}\left(1+\frac{E_{2}}{E_{1}}+\frac{\eta_{2}}{\eta_{3}}\right)+\frac{E_{1} E_{2} c}{\eta_{2} \eta_{3} \rho}\right\} \dot{q} \\
+\left\{\left[\frac{F}{A \rho}-v^{2}\right] \frac{E_{1} E_{2} \pi^{2}}{\eta_{2} \eta_{3}{ }^{2}} q+\frac{E_{1} \pi^{4}}{2 l^{4} \rho} \ddot{q} q^{2}+\frac{3 E_{1} \pi^{4}}{4 l^{4} \rho} \dot{q}^{2} q\right. \\
+ \\
\left.+\frac{E_{1} E_{2} \pi^{4}}{2 l^{4} \rho \eta_{2} \eta_{3}} \dot{q} q^{2}\right\}=0,
\end{aligned}
$$

where the constitutive model of yarns is based on the fourelement model, and its parameters are $E_{1}=35.31 \mathrm{cN} / \mathrm{tex}, E_{2}=$ $115.79 \mathrm{cN} / \mathrm{tex}, \quad \eta_{2}=9.11 \times 10^{3} \mathrm{cN} . \mathrm{s} / \mathrm{tex}, \quad \eta_{3}=1.03 \times 10^{3}$ cN.s/tex. The yarn density is $\rho=0.91 \mathrm{~g} / \mathrm{cm}^{-3}$, the cross-sectional area is $A=0.33 \mathrm{~cm}^{2} . F$ is the yarn tension. The fluctuation of yarn speed is ignored, and the constant speed is $v=0.3 \mathrm{~m} / \mathrm{s}$, damping coefficient is $c=0.1$.

By substituting the above parameters in equation (6), a change in tension of $0.25 \mathrm{~N}$ can cause a yarn amplitude change of $1 \mathrm{~mm}$. A tension change of $0.25 \mathrm{~N}$ can make the pile height deviate from the default pile height by $0.857 \mathrm{~mm}$. Therefore, a change in yarn amplitude of $1 \mathrm{~mm}$ can cause a velvet height change of $0.857 \mathrm{~mm}$. The maximum amplitude of the yarn at the jacquard part reaches $3.75 \mathrm{~mm}$, which can cause $3.15 \mathrm{~mm}$ variation of pile height. For the jacquard carpet with the resolution of $1 \mathrm{~mm}$, the vibration amplitude of the yarn is large and it needs to be controlled by the corresponding controller. 


\section{Yarn Vibration Control Based on Sliding Mode Control}

3.1. Basic Principle of Sliding Mode Control Algorithm. Sliding mode control is a typical and special nonlinear control method with strong robustness. The core of sliding mode control is to design sliding surface according to the desired dynamic characteristics of the system. Through a sliding mode controller, all the moving points outside the sliding surface can reach the sliding surface within a limited time.

The design of sliding mode variable structure control system can be divided into two steps as follows: (1) according to the system description of the controlled object, the suitable sliding mode function is selected; (2) the appropriate control law is obtained. The appropriate control law can make all the motion trajectory point to the sliding surface and reach the dynamic quality requirements of the control system. The proper Lyapunov function is selected to ensure the stability of the system.

3.2. System Description of the Controlled Yarn. To control the yarn vibration, the vibration amplitude $q$, speed $\dot{q}$, acceleration $\ddot{q}$, and the rate of acceleration $\dddot{q}$ of yarn are controlled by using the sliding mode variable structure control method based on tension control. The schematic diagram of sliding mode control is shown in Figure 2. The tension sensor is used to detect the tension online in real time, and then the vibration characteristic values of $q, \dot{q}, \ddot{q}$, and $\dddot{q}$ are calculated. If these values are all zero, the tension is monitored in real time. If not all is zero, the tension control force $u_{t}$ is calculated by the sliding mode control algorithm, and the tension is changed by the corresponding actuator.

According to equation (6), the transverse vibration control equation of yarn under the combined action of control force $u_{t}$ and random disturbance $d(t)$ is

$$
\begin{aligned}
\dddot{q}+[ & \left.\frac{E_{1}}{\eta_{2}}\left(1+\frac{E_{2}}{E_{1}}+\frac{\eta_{2}}{\eta_{3}}\right)+\frac{c}{\rho}\right] \dddot{q} \\
& +\left[\left\{\left[\frac{u_{t}}{A \rho}-v^{2}\right] \frac{\pi^{2}}{l^{2}}+\frac{E_{1} E_{2}}{\eta_{2} \eta_{3}}+\frac{c E_{1}}{\eta_{2} \rho}\left(1+\frac{E_{2}}{E_{1}}+\frac{\eta_{2}}{\eta_{3}}\right)\right\}\right] \ddot{q} \\
& +\left\{\left[\frac{u_{t}}{A \rho}-v^{2}\right] \frac{E_{1} \pi^{2}}{\eta_{2} l^{2}}\left(1+\frac{E_{2}}{E_{1}}+\frac{\eta_{2}}{\eta_{3}}\right)+\frac{E_{1} E_{2} c}{\eta_{2} \eta_{3} \rho}\right\} \dot{q} \\
& +\left\{\left[\frac{u_{t}}{A \rho}-v^{2}\right] \frac{E_{1} E_{2} \pi^{2}}{\eta_{2} \eta_{3} l^{2}} q+\frac{E_{1} \pi^{4}}{2 l^{4} \rho} \ddot{q} q^{2}+\frac{3 E_{1} \pi^{4}}{4 l^{4} \rho} \dot{q}^{2} q\right. \\
& \left.+\frac{E_{1} E_{2} \pi^{4}}{2 l^{4} \rho \eta_{2} \eta_{3}} \dot{q} q^{2}+d(t)\right\}=0 .
\end{aligned}
$$

Define a four-dimensional state vector,

$$
\left[\begin{array}{l}
x_{1} \\
x_{2} \\
x_{3} \\
x_{4}
\end{array}\right]=\left[\begin{array}{c}
q \\
\dot{q} \\
\ddot{q} \\
\dddot{q}
\end{array}\right]
$$

The transverse vibration control equation is rewritten as

$$
\left\{\begin{array}{l}
\dot{x}_{1}=x_{2}, \\
\dot{x}_{2}=x_{3}, \\
\dot{x}_{3}=x_{4}, \\
\dot{x}_{4}=f\left(x_{1}, x_{2}, x_{3}, x_{4}\right)+b\left(x_{1}, x_{2}, x_{3}\right) u_{t}+d(t),
\end{array}\right.
$$

where $f\left(x_{1}, x_{2}, x_{3}, x_{4}\right)=-m_{1} x_{4}-m_{2} x_{3}-m_{3} x_{2}-m_{4} x_{1}-$ $m_{5} x_{3} x_{1}^{2}-m_{6} x_{2}^{2} x_{1}-m_{7} x_{2} x_{1}^{2}, \quad b\left(x_{1}, x_{2}, x_{3}\right)=-m_{8} x_{3}-m_{9} x_{2}$ $-m_{10} x_{1}, m_{1}=E_{1} / \eta_{2}\left(1+\left(E_{2} / E_{1}\right)+\left(\eta_{2} / \eta_{3}\right)\right)+(c / \rho), m_{2}=$ $\left(E_{1} E_{2} / \eta_{2} \eta_{3}\right)+\left(c E_{1} / \eta_{2} \rho\right)\left(1+\left(E_{2} / E_{1}\right)+\left(\eta_{2} / \eta_{3}\right)\right)-\left(\pi^{2} v^{2} / l^{2}\right)$, $m_{3}=\left(E_{1} E_{2} c / \eta_{2} \eta_{3} \rho\right)-\left(E_{1} \pi^{2} v^{2} / \eta_{2} l^{2}\right)\left(1+\left(E_{2} / E_{1}\right)+\left(\eta_{2} / \eta_{3}\right)\right)$, $m_{4}=E_{1} E_{2} \pi^{2} v^{2} / \eta_{2} \eta_{3} l^{2}, m_{5}=E_{1} \pi^{4} / 2 l^{4} \rho, m_{6}=3 E_{1} \pi^{4} / 4 l^{4} \rho$, $m_{7}=E_{1} E_{2} \pi^{4} / 2 l^{4} \rho \eta_{2} \eta_{3}, \quad m_{8}=\pi^{2} / A \rho l^{2}, \quad m_{9}=E_{1} \pi^{2} / A \rho \eta_{2} l^{2}$ $\left(\left(1+\left(E_{2} / E_{1}\right)+\left(\eta_{2} / \eta_{3}\right)\right), m_{10}=E_{1} E_{2} \pi^{2} / A \rho \eta_{2} \eta_{3} l^{2}\right.$.

The control target is

$$
x_{i} \longrightarrow 0, \quad i=1,2,3,4 \text {. }
$$

The error equation is

$$
\left\{\begin{array}{l}
e_{1}=x_{1}, \\
e_{2}=\dot{e}_{1}=x_{2}, \\
e_{3}=\dot{e}_{2}=\dot{x}_{2}=x_{3}, \\
e_{4}=\dot{e}_{3}=x_{4} .
\end{array}\right.
$$

3.3. Design of Sliding Mode Controller. The design of sliding mode variable structure control system consists of two parts, namely, choosing the appropriate sliding mode function and control law. First, the sliding mode function is selected as

$$
s=c_{1} e_{1}+c_{2} e_{2}+c_{3} e_{3}+e_{4},
$$

where $c_{i}>0, \quad i=1,2,3$.

The control law designed in this paper is the sum of equivalent control $u_{\mathrm{eq}}$ and switching control $u_{\mathrm{sw}}$. The equivalent control keeps the state of the system on the sliding surface, and the switching control forces the system to slide on the sliding surface. Therefore, the control law is as follows

$$
u_{t}=u_{\mathrm{eq}}+u_{\mathrm{sw}} \text {. }
$$

Under the action of equivalent control law $u_{\text {eq }}$, when the system moves along the sliding surface, the system moves steadily, then $\dot{s}=0$. Based on the derivation of equation (12), it can be obtained that

$$
\begin{aligned}
\dot{s}= & c_{1} \dot{e}_{1}+c_{2} \dot{e}_{2}+c_{3} \dot{e}_{3}+\dot{e}_{4} \\
= & c_{1} x_{2}+c_{2} x_{3}+c_{3} x_{4}+f\left(x_{1}, x_{2}, x_{3}, x_{4}\right) \\
& +b\left(x_{1}, x_{2}, x_{3}\right) u_{t}+d(t) .
\end{aligned}
$$

Taking $\dot{s}=0$, the equivalent control law $u_{\mathrm{eq}}$ is 


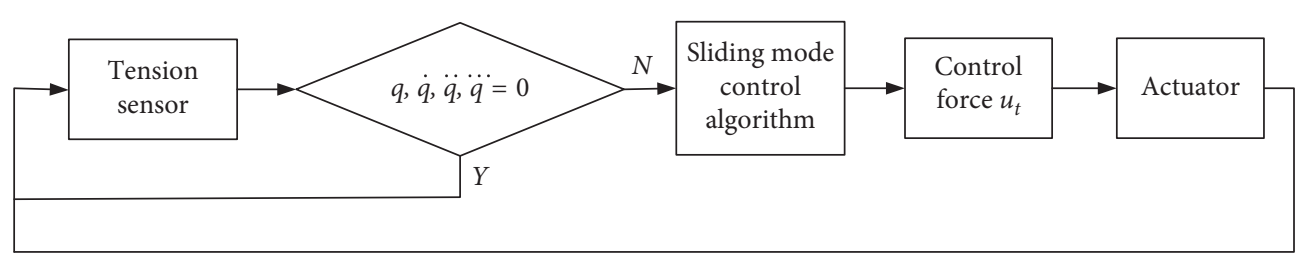

Figure 2: The schematic diagram of sliding mode control.

$u_{\mathrm{eq}}=-\frac{1}{b}\left[c_{1} x_{2}+c_{2} x_{3}+c_{3} x_{4}+f\left(x_{1}, x_{2}, x_{3}, x_{4}\right)\right]$.

The switch control is set as

$$
u_{\mathrm{sw}}=-\frac{1}{b}[M \operatorname{sgn}(s)+\lambda s]
$$

where $M>0, \lambda>0, \operatorname{sgn}(s)$ is a symbolic function:

$$
\operatorname{sgn}(s)= \begin{cases}1, & s \geq 0, \\ -1, & s<0 .\end{cases}
$$

Substituting the equations (13), (15), and (16) in equation (14), it can be obtained that

$$
\begin{aligned}
\dot{s}= & c_{1} x_{2}+c_{2} x_{3}+c_{3} x_{4}+f\left(x_{1}, x_{2}, x_{3}, x_{4}\right) \\
& +b\left(x_{1}, x_{2}, x_{3}\right) u_{t}+d(t)=-M \operatorname{sgn}(s)-\lambda s+d(t) .
\end{aligned}
$$

To prove the stability of the system, take the Lyapunov function as $V=1 / 2 s^{2}$, let $|d(t)| \leq \bar{d}$ and $M=\beta \bar{d}+\rho$, so

$$
\dot{V}=s \dot{s}=s[-(\beta \bar{d}+\rho) \operatorname{sgn}(s)-\lambda s+d(t)] \leq-\rho|s|-\lambda s^{2} \leq 0,
$$

then the system is stable. From the above analysis, we can see that $s \dot{s} \leq 0$, then $t>t_{0}, s=0$. When $s=0$,

$$
e_{4}=-c_{1} e_{1}-c_{2} e_{2}-c_{3} e_{3} \text {. }
$$

Order

$$
\mathbf{A}=\left[\begin{array}{ccc}
0 & 1 & 0 \\
0 & 0 & 1 \\
-c_{1} & -c_{2} & -c_{3}
\end{array}\right]
$$

In order to make the eigenvalue of $\mathbf{A}$ negative, the following condition should be satisfied:

$$
\left|\mathbf{A}-\lambda_{0} \mathbf{I}\right|=\left|\begin{array}{ccc}
-\lambda_{0} & 1 & 0 \\
0 & -\lambda_{0} & 1 \\
-c_{1} & -c_{2} & -c_{3}-\lambda_{0}
\end{array}\right|=-\lambda_{0}^{3}-c_{3} \lambda_{0}^{2}-c_{2} \lambda_{0}-c_{1}=0
$$

The values of $c_{1}, c_{2}$, and $c_{3}$ should be satisfied:

$$
\lambda_{0}^{3}+c_{3} \lambda_{0}^{2}+c_{2} \lambda_{0}+c_{1}=0 \text {. }
$$

3.4. Simulation Calculation and Result Analysis. Take the disturbance $d(t)=\sin t, c_{1}=27, c_{2}=27, \quad c_{3}=9, \quad \beta=1$, $\bar{d}=1, \rho=1$, and $\lambda=1$. The simulation time is $20 \mathrm{~s}$. Using control laws of equations (13), (15), and (16), the system is simulated by Matlab/Simulink. The main program block diagram is shown in Figure 3. In Figure 3, the controller_function is a controller subroutine, and the controlled_function is a controlled object subroutine.

When the control is not applied, the yarn response curves at the output side of the jacquard roller are shown in Figure 4. After applying the sliding mode control law, the response curves of $q, \dot{q}, \ddot{q}$, and $\dddot{q}$ are shown in Figure 5. As shown in Figure 4, when the control is not applied, the amplitude of yarn $q$ varies within the range of $-3.75 \sim 3.75 \mathrm{~mm}, \dot{q}$ varies within the range of $-0.19 \sim 0.19 \mathrm{~m} /$ $\mathrm{s}, \ddot{q}$ varies within the range of $-0.1 \sim 0.1 \mathrm{~m} / \mathrm{s}^{2}$, and $\dddot{q}$ varies within the range of $-5.16 \sim 5.16 \mathrm{~m} / \mathrm{s}^{3}$. The amplitude, speed, acceleration, and the rate of acceleration varies greatly, and the attenuation decreases slowly with time. As shown in Figure 5, when the control is applied, the response values of yarn vibration vary greatly in the former $4 \mathrm{~s}$. After $4 \mathrm{~s}$, the response characteristic curves maintain periodic changes. $q$ varies within the range of $-0.058 \sim 0.058 \mathrm{~m}, \dot{q}$ varies within the range of $-0.00441 \sim 0.00441 \mathrm{~m} / \mathrm{s}, \ddot{q}$ varies within the range of $-0.041 \sim 0.041 \mathrm{~m} / \mathrm{s}^{2}$, and $\dddot{q}$ varies within the range of $-0.412 \sim 0.412 \mathrm{~m} / \mathrm{s}^{3}$. From the comparison between Figures 4 and 5, the maximum amplitude without control is $3.75 \mathrm{~mm}$, and the maximum value of amplitude with control is changed to $0.058 \mathrm{~mm}$, and the maximum value of $\dot{q}$ is reduced from $0.19 \mathrm{~m} / \mathrm{s}$ to $0.00441 \mathrm{~m} / \mathrm{s}$, the maximum value of $\ddot{q}$ is reduced from $0.1 \mathrm{~m} / \mathrm{s}^{2}$ to $0.041 \mathrm{~m} / \mathrm{s}^{2}$, and the maximum value of $\dddot{q}$ is reduced from $5.16 \mathrm{~m} / \mathrm{s}^{3}$ to $0.412 \mathrm{~m} / \mathrm{s}^{3}$. Therefore, the sliding mode controller is reasonable and effective, and the vibration response of the yarn has been significantly suppressed.

The control force $u_{t}$ is shown in Figure 6. To achieve the above control effect, the applied control force does not exceed $1 \mathrm{~N}$, and the general actuator can meet the requirements. However, after the stability of the vibration response, the sliding mode control force still needs to be switched at high frequency. The actuator needs to respond quickly, so the controller is greatly restricted in practical application.

\section{Yarn Vibration Control Based on Quasifuzzy Sliding Mode Control}

To reduce chattering effectively, the sliding mode controller should be optimized. This article will reduce buffeting from two aspects. On the one hand, in the above sliding mode control, the sign function of ideal sliding mode is adopted. In practical engineering, the ideal sliding mode does not exist. To eliminate chattering, Slotine and Sastry [20] uses quasisliding mode control to limit the trajectory of the system to a certain boundary layer of the ideal sliding mode. The 


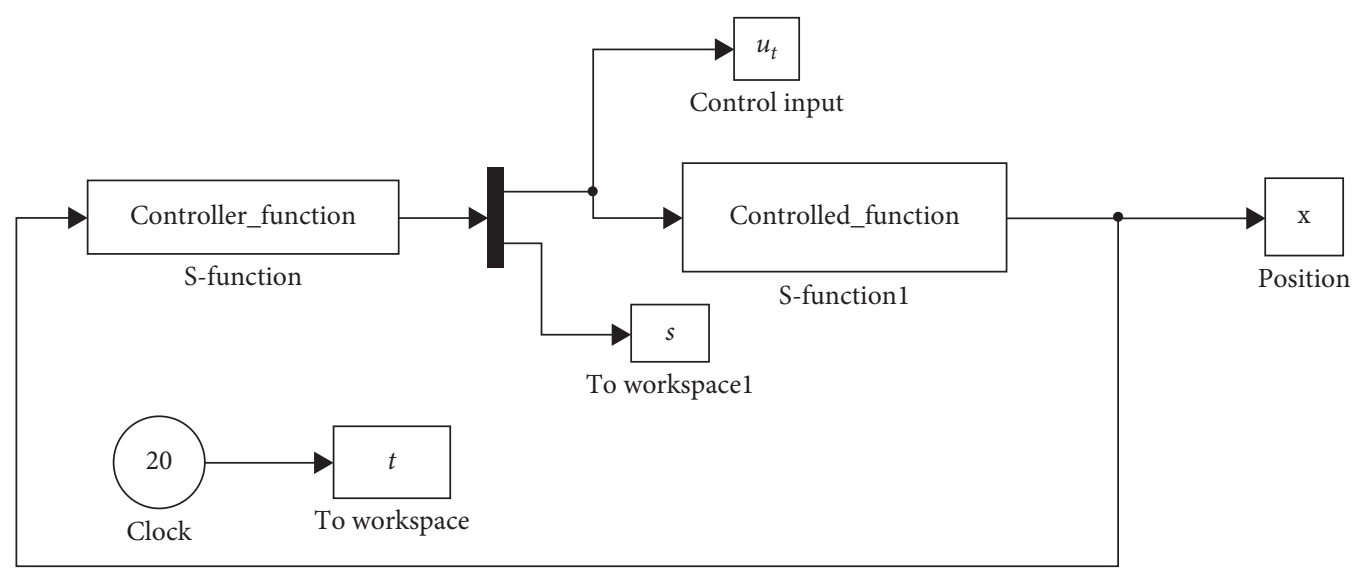

FigURE 3: Main program block diagram.

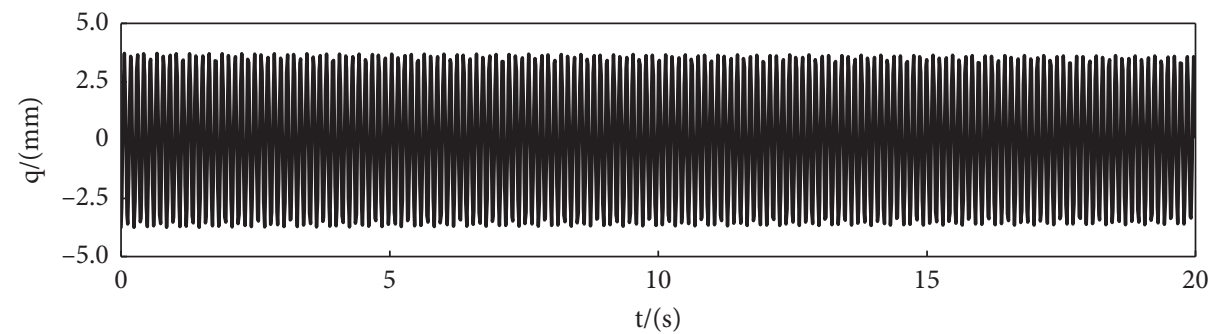

(a)

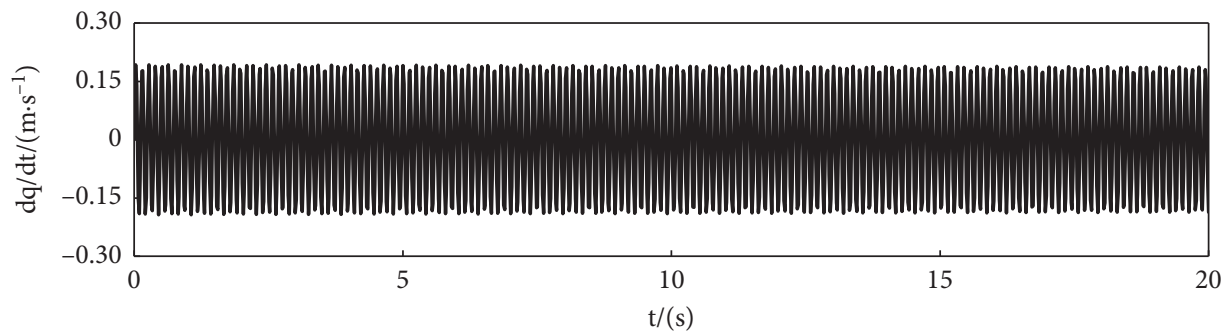

(b)

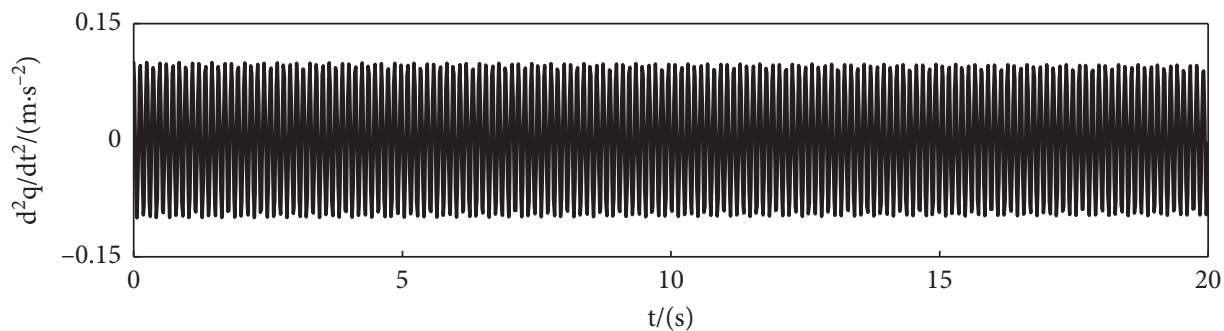

(c)

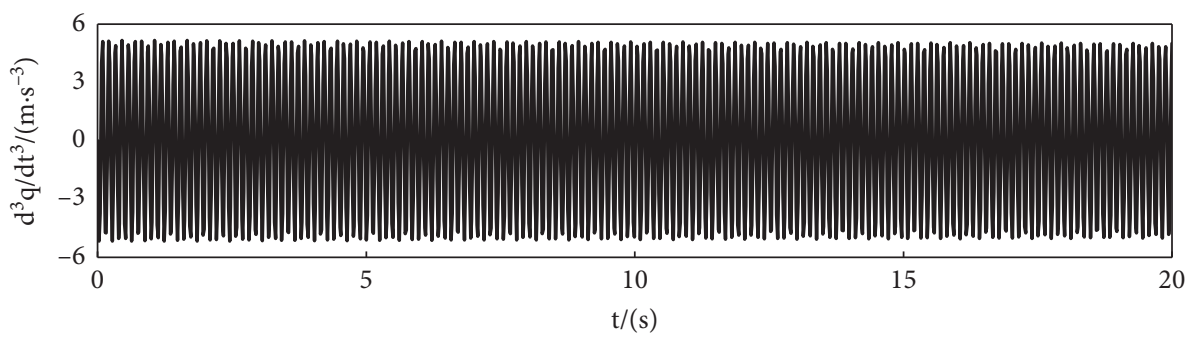

(d)

FIGURE 4: Response curve without control using sliding mode control method. 


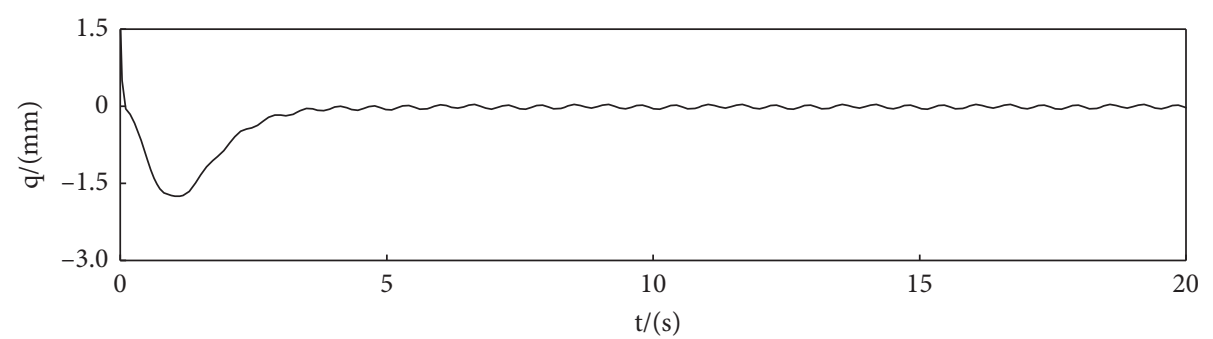

(a)

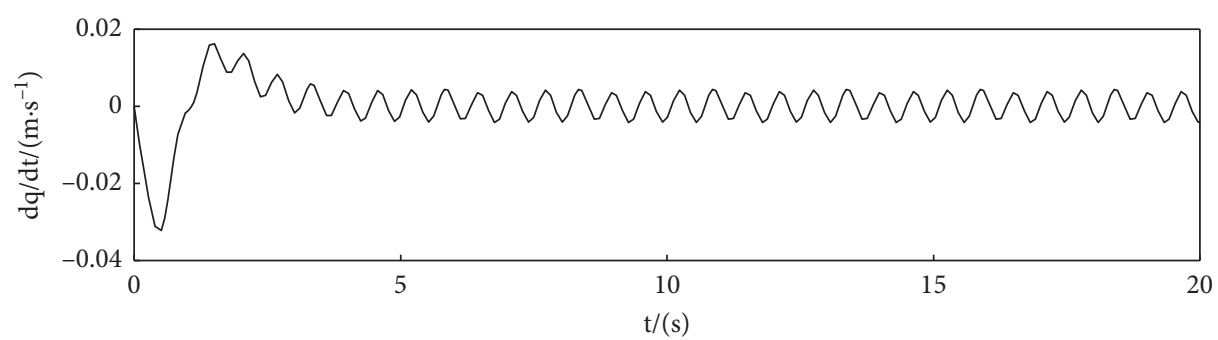

(b)

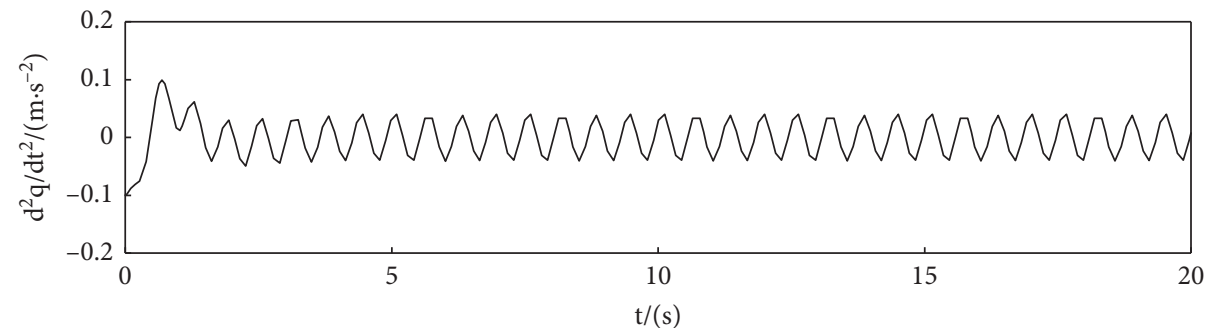

(c)

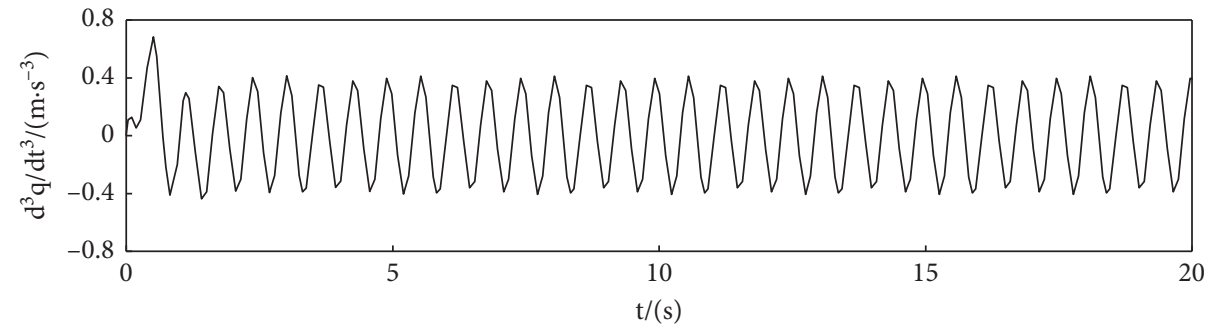

(d)

FIGURE 5: Response curve with control using sliding mode control method.

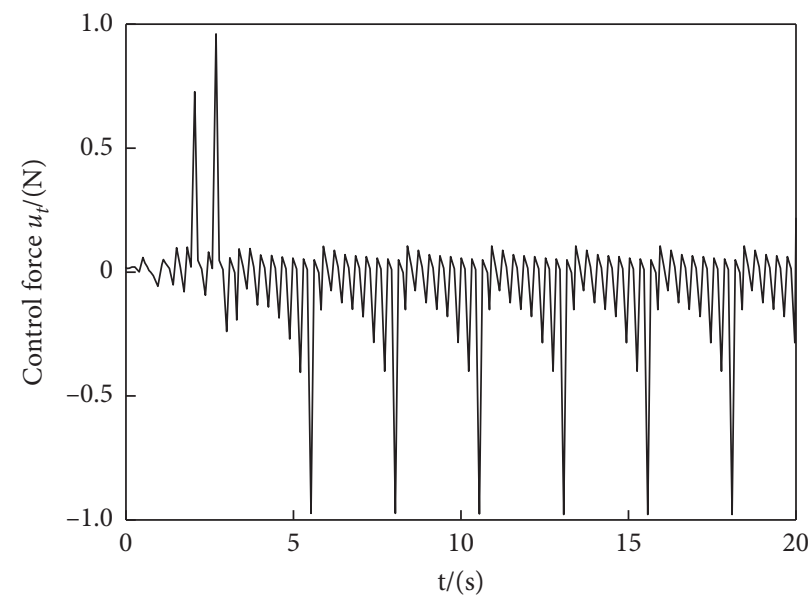

Figure 6: Control force using mode control method. 
quasisliding mode control does not require the control switching on the switching surface, but the control switching in the boundary layer, which weakens the buffeting and is widely used in practical engineering.

On the other hand, in the above sliding mode control, the control law is composed of equivalent control and switching control. The robustness of sliding mode control is guaranteed by switching control, and the chattering of sliding mode control is also caused by switching control. In order to eliminate chattering, we should ensure that the system has strong robustness while minimizing the switching control. Therefore, in order to achieve this goal, the fuzzy rules can be used to fuzzily the switching control and to eliminate the buffeting.

4.1. Design of Fuzzy Sliding Mode Controller Based on Quasisliding Mode Control. The design of fuzzy sliding mode controller is started from two aspects. On the one hand, the quasisliding mode control is used, that is, the saturation function $\operatorname{sat}(s)$ is used to replace the symbolic function $\operatorname{sgn}(s)$. The saturation function sat $(s)$ is as follows:

$$
\operatorname{sat}(s)= \begin{cases}1, & s>\Delta \\ k s, & |s| \leq \Delta \\ -1, & s<-\Delta\end{cases}
$$

where $k=1 / \Delta, \Delta$ is the boundary layer.

On the other hand, the switching control item deals with fuzzy measure. Therefore, the control law $u_{t}^{\prime}$ is

$$
u_{t}^{\prime}=u_{\mathrm{eq}}+\mu \cdot u_{s}
$$

where $\mu$ is fuzzy factor.

The fuzzy rule is shown in Table 1. In Table 1, fuzzy sets $\mathrm{N}, \mathrm{Z}$, and $\mathrm{P}$, respectively, denote "negative," "zero," and "positive." From Table 1, when $s=0$, the system is stable on the sliding surface, and the system control law is composed of equivalent control, $\mu=0$. When $s \neq 0$, the system control law is composed of the equivalent control term and the switching control. The membership function of the sliding mode function $s$ and fuzzy factor $\mu$ is shown in Figure 7 .

The super-twisting algorithm [21] is well known as a good candidate robust controller that reduces the chattering phenomenon. In this paper, we compare results obtained using quasifuzzy sliding mode control algorithm with those obtained using the super-twisting algorithm. The control law $u_{t}$ :

$$
\begin{aligned}
u_{t}= & \frac{1}{b}\left(-f\left(x_{1}, x_{2}, x_{3}, x_{4}\right)\right)-c_{1} x_{2}-c_{2} x_{3}-c_{3} x_{4} \\
& -k_{1} s-k_{2}|s|^{1 / 2} \operatorname{sgn}(s)+w, \\
\dot{w}= & -k_{3} \operatorname{sgn}(s),
\end{aligned}
$$

where $k_{1}>0, k_{2}>2 \sqrt{\bar{d}}, k_{3}>\max \left\{\bar{d}-0.5 k_{2}^{2}, \bar{d}\left(k_{2} / k_{1}\right)-2 k_{2}^{2}\right\}$.

4.2. Simulation and Results Analysis. To get accurate calculation results, the value of boundary layer is particularly critical. The larger the thickness of the boundary layer is, the
TABLE 1: Control rule table.

\begin{tabular}{llll}
\hline$s$ & $\mathrm{~N}$ & $\mathrm{Z}$ & $\mathrm{P}$ \\
$\mu$ & $\mathrm{P}$ & $\mathrm{Z}$ & $\mathrm{P}$ \\
\hline
\end{tabular}

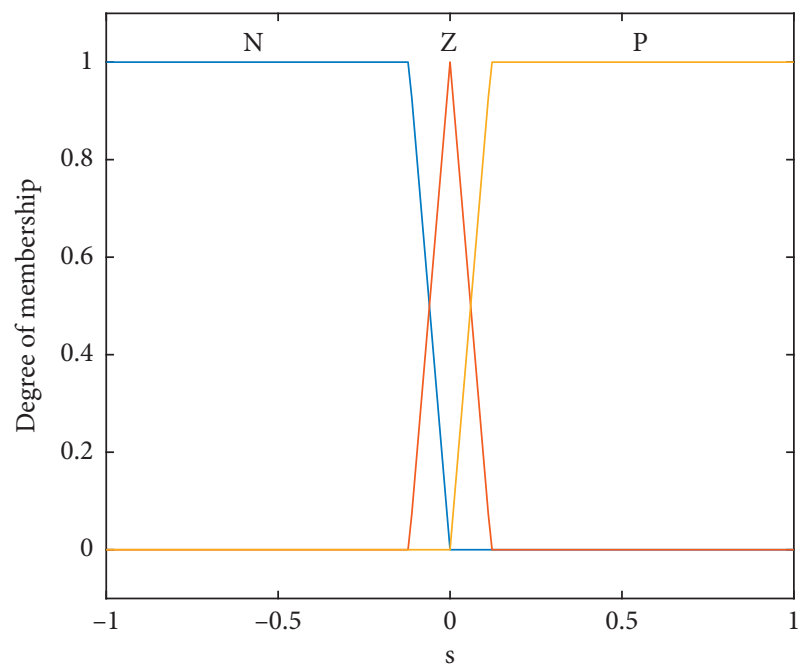

(a)

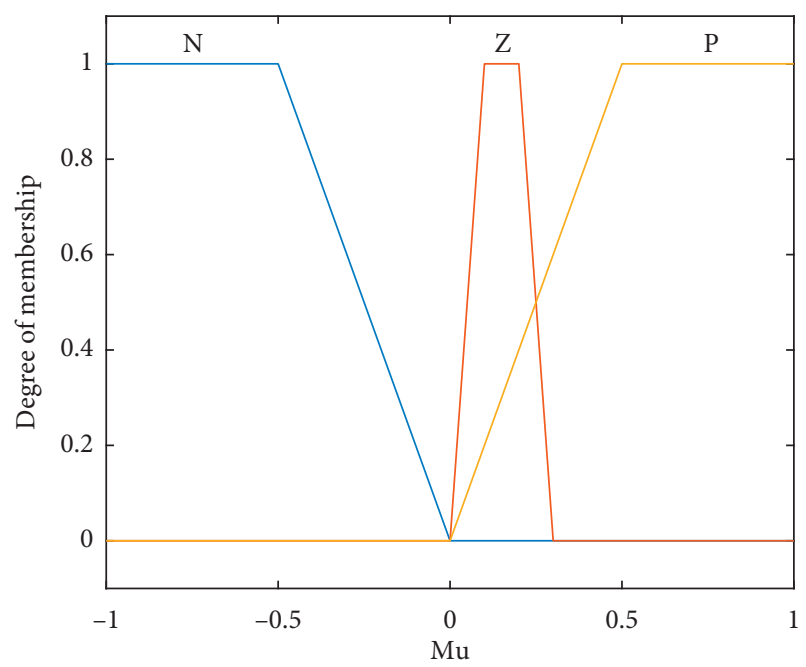

(b)

Figure 7: Membership function. (a) Membership function of the sliding mode function s. (b) Membership function of fuzzy factor $\mu$.

smaller the chattering is, but the worse the control effect is. Conversely, the smaller the thickness of the boundary layer is, the larger the chattering is, and the better the control effect is. To get the best antichattering control force, the thickness of the boundary layer is defined to be 0.05 through a number of trial calculations. The control law of equation (25) is adopted, and the other parameters are the same as those applied to the sliding mode controller. When using the super-twisting sliding mode control, the parameter $k_{1}$ is set to $1, k_{2}$ is set to 3 , and $k_{3}$ is set to 2 . The response curves are shown in Figure 8, and the control force is shown in Figure 9.

As shown in Figure 8, when the fuzzy sliding mode controller is applied, the response values of yarn vibration vary greatly in the former $2 \mathrm{~s}$. After $2 \mathrm{~s}$, the response 


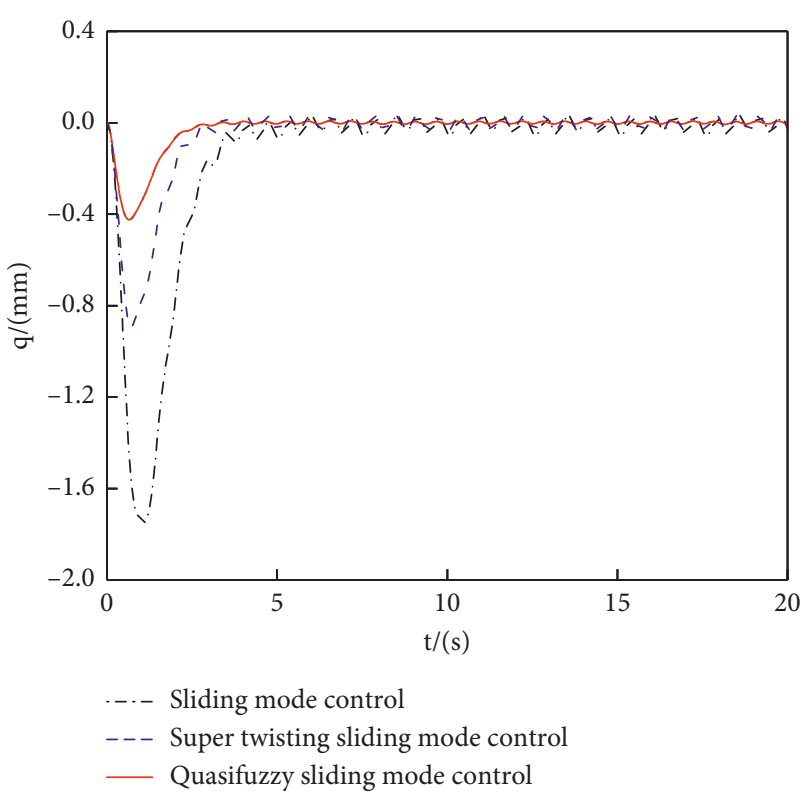

(a)

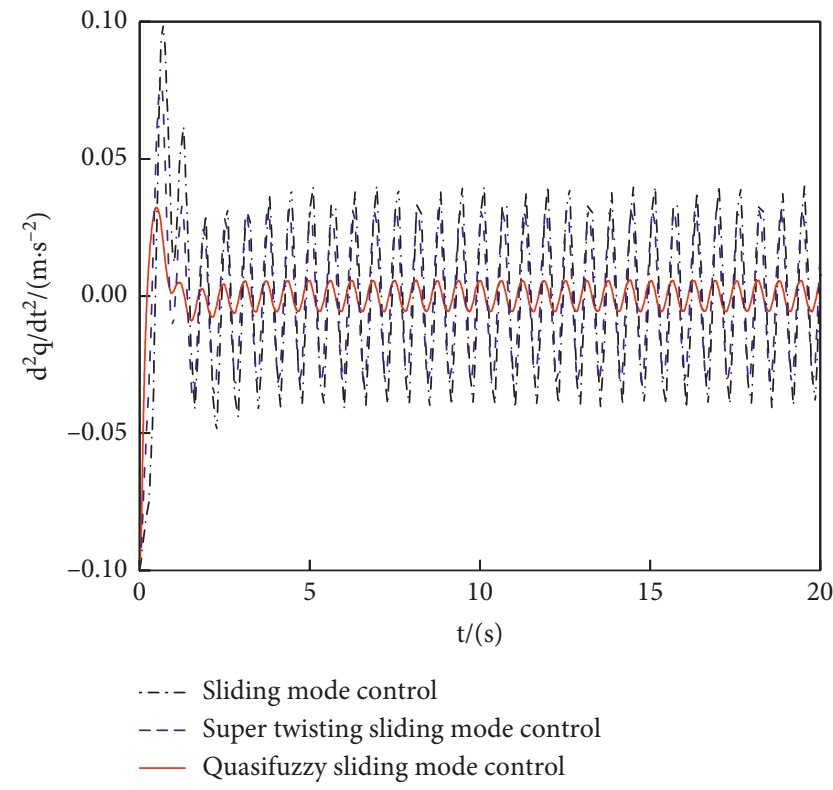

(c)

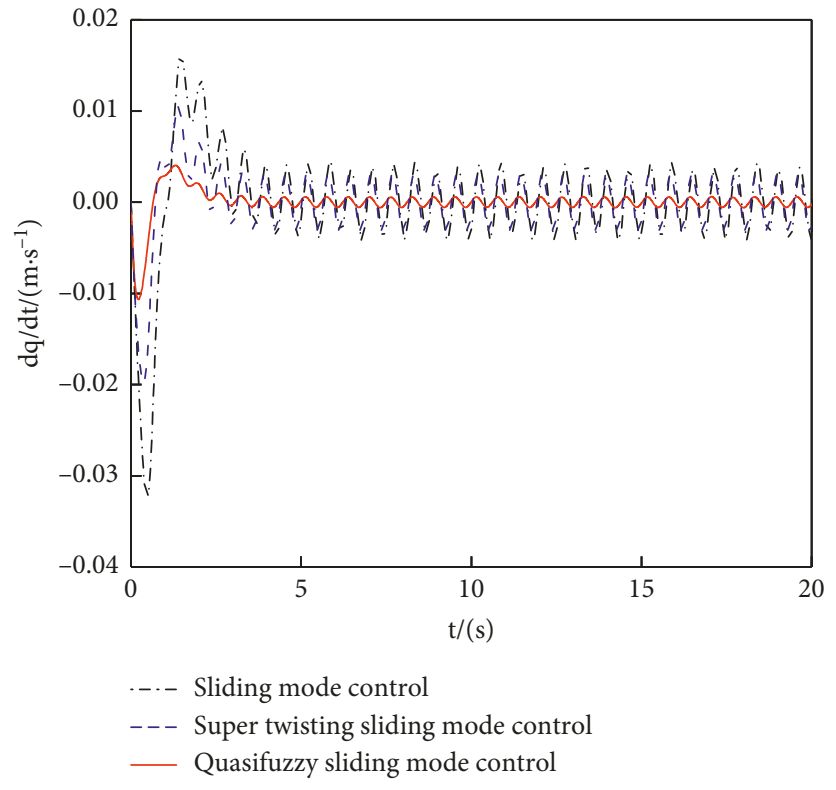

(b)

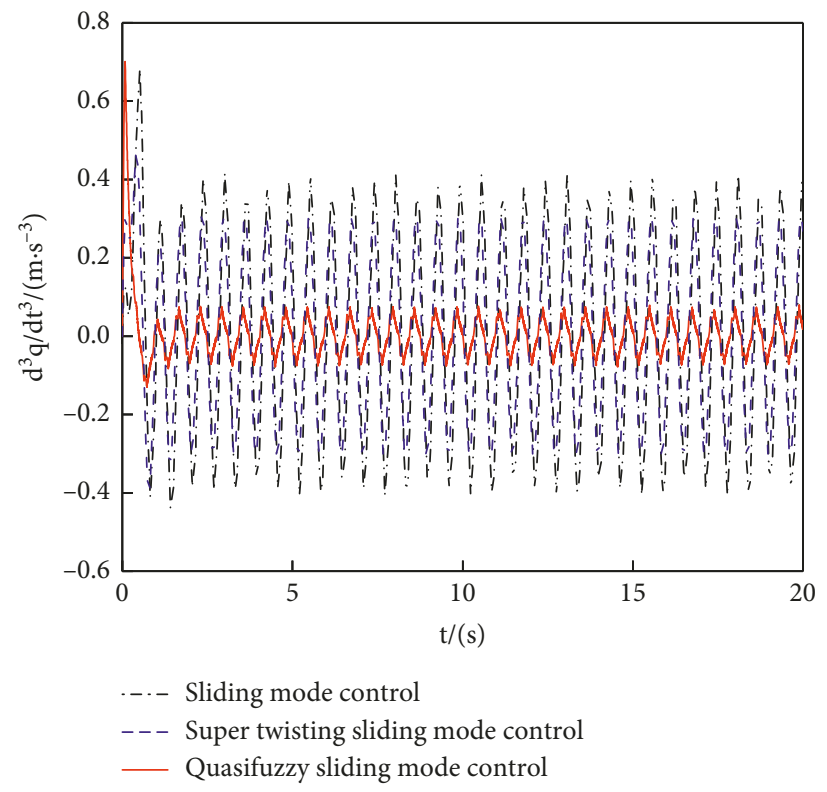

(d)

FIGURE 8: Response characteristic curves. (a) Response curve of $q$. (b) Response curve of $\dot{q}$. (c) Response curve of $\ddot{q}$. (d) Response curve of $\dddot{q}$.

characteristic curves maintain periodic changes. Compared with sliding mode control, quasifuzzy sliding mode control achieves stability in a relatively short time and responds quickly. $q$ varies within the range of $-0.00732 \sim 0.00732 \mathrm{~mm}$, $\dot{q}$ varies within the range of $-0.000611 \sim 0.000611 \mathrm{~m} / \mathrm{s}, \ddot{q}$ varies within the range of $-0.0057 \sim 0.0057 \mathrm{~m} / \mathrm{s}^{2}, \dddot{q}$ varies within the range of $-0.0784 \sim 0.0784 \mathrm{~m} / \mathrm{s}^{3}$. The maximum amplitude is reduced from $3.75 \mathrm{~mm}$ to $0.00732 \mathrm{~mm}$ compared with that without sliding mode control. And the maximum value of $\dot{q}$ is reduced from $0.19 \mathrm{~m} / \mathrm{s}$ to $0.000611 \mathrm{~m} / \mathrm{s}$, the maximum value of $\ddot{q}$ is reduced from $0.1 \mathrm{~m} / \mathrm{s}^{2}$ to $0.000611 \mathrm{~m} / \mathrm{s}$, the maximum value of $q$ is reduced from $5.16 \mathrm{~m} / \mathrm{s}^{3}$ to $0.0784 \mathrm{~m} / \mathrm{s}^{3}$. Compared with the sliding mode control, the maximum amplitude $q$ decreases by 8 times, $\dot{q}$ decreases by 7 times. $\ddot{q}$ decreases by 7 times, and $\dddot{q}$ decreases by 5 times. Therefore, the quasifuzzy sliding mode controller is more reasonable and effective, and the vibration response of the yarn is more restrained.

As shown in Figure 9, compared with the applied sliding mode control force, the maximum control force required by the quasisliding mode fuzzy controller is $0.57 \mathrm{~N}$, and a better control effect can be achieved with smaller force. In addition, when the fuzzy controller of quasisliding mode is used, the control force does not have high-frequency switching, and the change is relatively stable, which reduces the chattering of sliding mode control and can be applied well in 


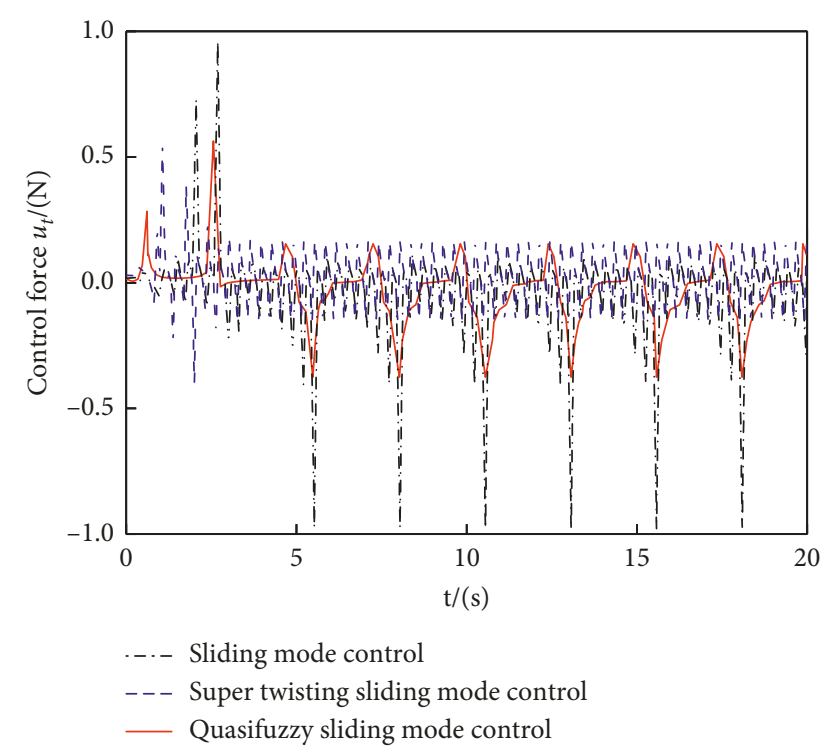

FIgURE 9: Fuzzy sliding mode control force.

engineering practice. Therefore, in the control of yarn vibration, the best control effect is obtained using the quasifuzzy sliding mode control, followed by super-twisting sliding mode control and sliding mode control.

\section{Conclusions}

The sliding mode control algorithm and quasisliding mode fuzzy sliding mode control algorithm is used to control the four parameters of yarn vibration characteristics. The results show the following:

(1) The yarn vibration amplitude $1 \mathrm{~mm}$ can cause the change of pile height $0.857 \mathrm{~mm}$. Compared with the high-resolution $1 \mathrm{~mm}$ of the multiloop high-tufted carpet machine, the error of the height caused by the yarn vibration cannot be neglected. Therefore, yarn vibration is a key factor affecting the quality of blanket surface.

(2) Using the sliding mode control algorithm, the maximum value of yarn amplitude changes from $3.75 \mathrm{~mm}$ to $0.058 \mathrm{~mm}$, and the control effect is obvious. Moreover, the control force required should not exceed $1 \mathrm{~N}$, and the general actuator can meet the requirements. However, the sliding mode control force still needs to be switched at high frequency, and there is severe chattering.

(3) Based on quasifuzzy sliding mode control algorithm, the maximum vibration value of yarn is $0.00732 \mathrm{~mm}$. Compared with the sliding mode control algorithm, the reduction is 8 times. The maximum control force of the quasisliding mode fuzzy controller is $0.57 \mathrm{~N}$, and a smaller force can achieve better control effect. In addition, when the quasisliding mode fuzzy controller is adopted, the control force does not have high-frequency switching, and the change is relatively stable, which reduces the chattering phenomenon of sliding mode control.

\section{Data Availability}

The data used to support the findings of this study are available from the corresponding author upon request.

\section{Conflicts of Interest}

The authors declare that they have no conflicts of interest.

\section{References}

[1] S. Huang, X. Chi, Y. Xu, and Y. Sun, "Dynamic characteristics of coupling shaft system in tufting machine based on the Riccati whole transfer matrix method," Proceedings of the Institution of Mechanical Engineers, Part C: Journal of Mechanical Engineering Science, vol. 231, no. 2, pp. 356-371, 2017.

[2] Y. Xu, Z. Sun, S. Huang, X. Sheng, and X. Chi, "Dynamic characteristic analysis of the needle multi-linkage mechanism in a carpet tufting machine's driving system," Fibres and Textiles in Eastern Europe, vol. 24, no. 3(117), pp. 103-109, 2016.

[3] V. K. Deolia, S. Purwar, and T. N. Sharma, "Stabilization of unknown nonlinear discrete-time delay systems based on neural network," Intelligent Control and Automation, vol. 03, no. 04, pp. 337-345, 2012.

[4] J. H. Perez-Cruz, I. Chairez, J. D. J. Rubio et al., "Identification and control of class of non-linear systems with non-symmetric deadzone using recurrent neural networks," IET Control Theory \& Applications, vol. 8, pp. 183-192, 2013.

[5] Y. Wang and H. Wu, "Adaptive robust backstepping control for a class of uncertain dynamical systems using neural networks," Nonlinear Dynamics, vol. 81, no. 4, pp. 1597-1610, 2015.

[6] W. M. Bessa, A. S. de Paula, and M. A. Savi, "Sliding mode control with adaptive fuzzy dead-zone compensation for uncertain chaotic systems," Nonlinear Dynamics, vol. 70, no. 3, pp. 1989-2001, 2012.

[7] V. Goyal, V. K. Deolia, and T. N. Sharma, "Robust sliding mode control for nonlinear discrete-time delayed systems based on neural network," Intelligent Control and Automation, vol. 06, no. 01, pp. 75-83, 2015.

[8] P. Singh, V. Goyal, V. K. Deolia, and T. N. Sharma, "Sliding mode control of uncertain nonlinear discrete delayed time system using Chebyshev neural network," Advances in Computer and Computational Sciences, vol. 553, pp. 527-540, 2017.

[9] H.-T. Yau, C.-C. Wang, C.-T. Hsieh, and C.-C. Cho, "Nonlinear analysis and control of the uncertain micro-electromechanical system by using a fuzzy sliding mode control design," Computers \& Mathematics with Applications, vol. 61, no. 8, pp. 1912-1916, 2011.

[10] M. Shi, J. Li, and C. He, "Synchronization of complex dynamical networks with nonidentical nodes and derivative coupling via distributed adaptive control," Mathematical Problems in Engineering, vol. 2013, Article ID 172608, 11 pages, 2013.

[11] A. S. Yıldız, S. Sivrioğlu, E. Zergeroğlu et al., "Nonlinear adaptive control of semi-active MR damper suspension with uncertainties in model parameters," Nonlinear Dynamics, vol. 79, no. 4, pp. 2753-2766, 2015.

[12] D.-C. Liaw, Y.-W. Liang, and C.-C. Cheng, "Nonlinear control for missile terminal guidance," Journal of Dynamic 
Systems, Measurement, and Control, vol. 122, no. 4, pp. 663-668, 2000.

[13] F. K. Yeh, H. H. Chien, and L. C. Fu, "Design of optimal midcourse guidance sliding-mode control for missiles with TVC," IEEE Transactions on Aerospace \& Electronic Systems, vol. 39, no. 3, pp. 824-837, 2003.

[14] M. Dansoko, H. Nkwawo, B. Diourté, F. Floret, R. Goma, and G. Kenné, "Robust multivariable sliding mode control design for generator excitation of marine turbine in multimachine configuration," International Journal of Electrical Power \& Energy Systems, vol. 63, pp. 423-428, 2014.

[15] R.-F. Fung, J.-S. Huang, Y.-C. Wang, and R.-T. Yang, "Vibration reduction of the nonlinearly traveling string by a modified variable structure control with proportional and integral compensations," International Journal of Mechanical Sciences, vol. 40, no. 6, pp. 493-506, 1998.

[16] J.-S. Huang, P. C.-P. Chao, R.-F. Fung, and C.-L. Lai, "Parametric control of an axially moving string via fuzzy sliding-mode and fuzzy neural network methods," Journal of Sound and Vibration, vol. 264, no. 1, pp. 177-201, 2003.

[17] X. Yu and W. Zhang, "Transverse vibration control of an axially moving string system by variable structure control," Journal of Fuzhou University (Natural Science Edition), vol. 40, pp. 217-221, 2012.

[18] Y. Xu, Z. Sun, Z. Meng et al., "Research on yarn tension modeling in carpet tufting equipment system," Journal of Manufacturing Science \& Engineering, vol. 133, article 031002, 2011.

[19] S. Huang, Vibration Characteristics Analysis and Response Control of Key Components of Tufting Carpet Machine, Donghua University, Shanghai, China, 2017.

[20] J. J. Slotine and S. S. Sastry, "Tracking control of non-linear systems using sliding surfaces, with application to robot manipulators," International Journal of Control, vol. 38, pp. 132-135, 1983.

[21] A. Levant, "Sliding order and sliding accuracy in sliding mode control," International Journal of Control, vol. 58, no. 6, pp. 1247-1263, 1993. 


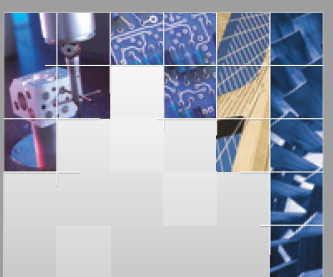

\section{Enfincering}
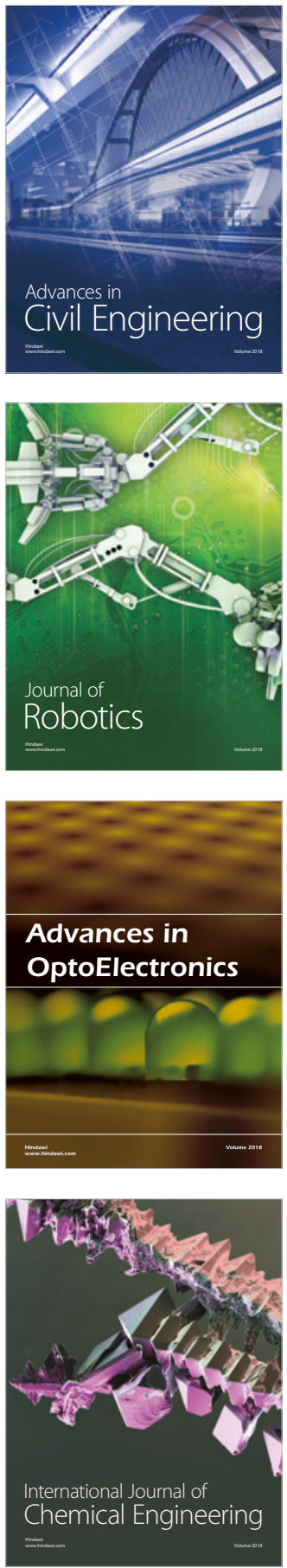

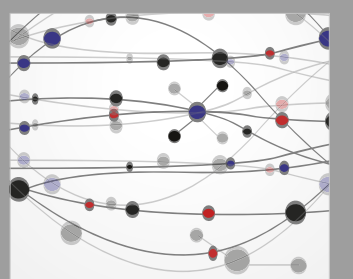

\section{Rotating \\ Machinery}

The Scientific World Journal

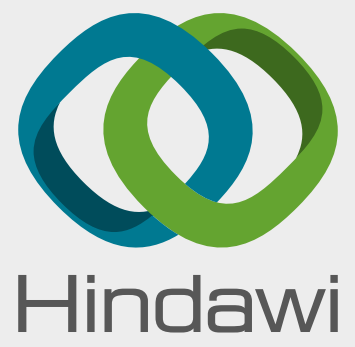

Submit your manuscripts at

www.hindawi.com
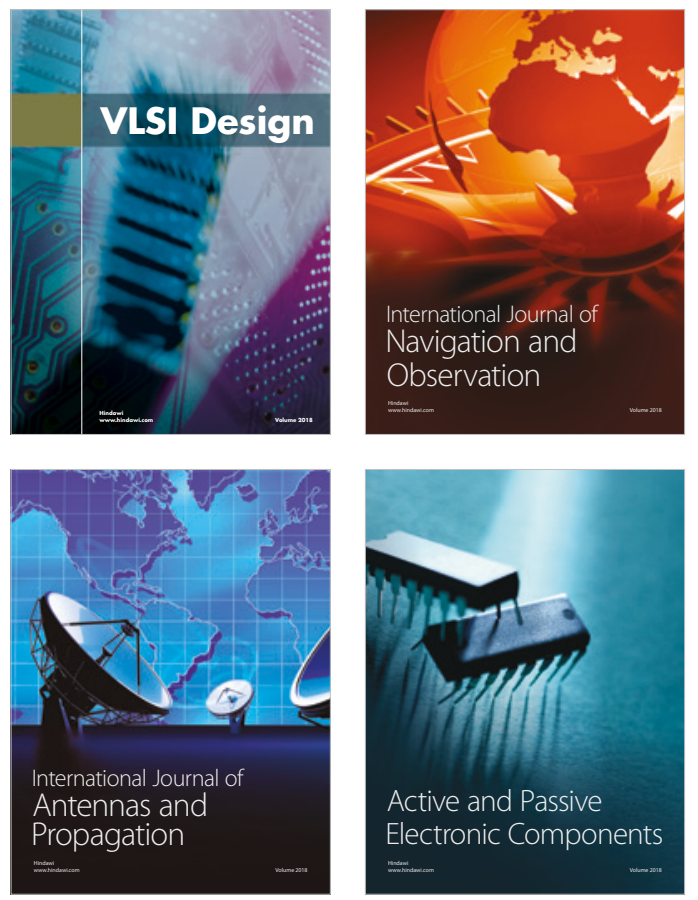
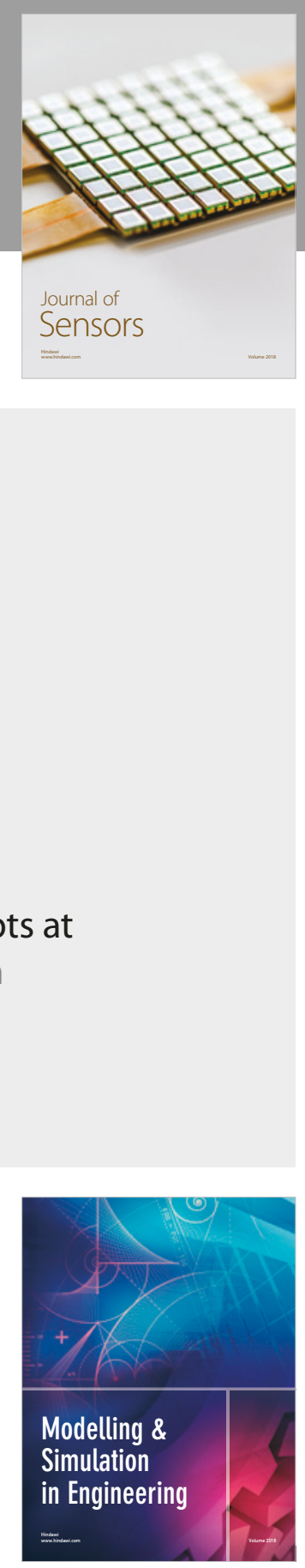

\section{Advances \\ Multimedia}
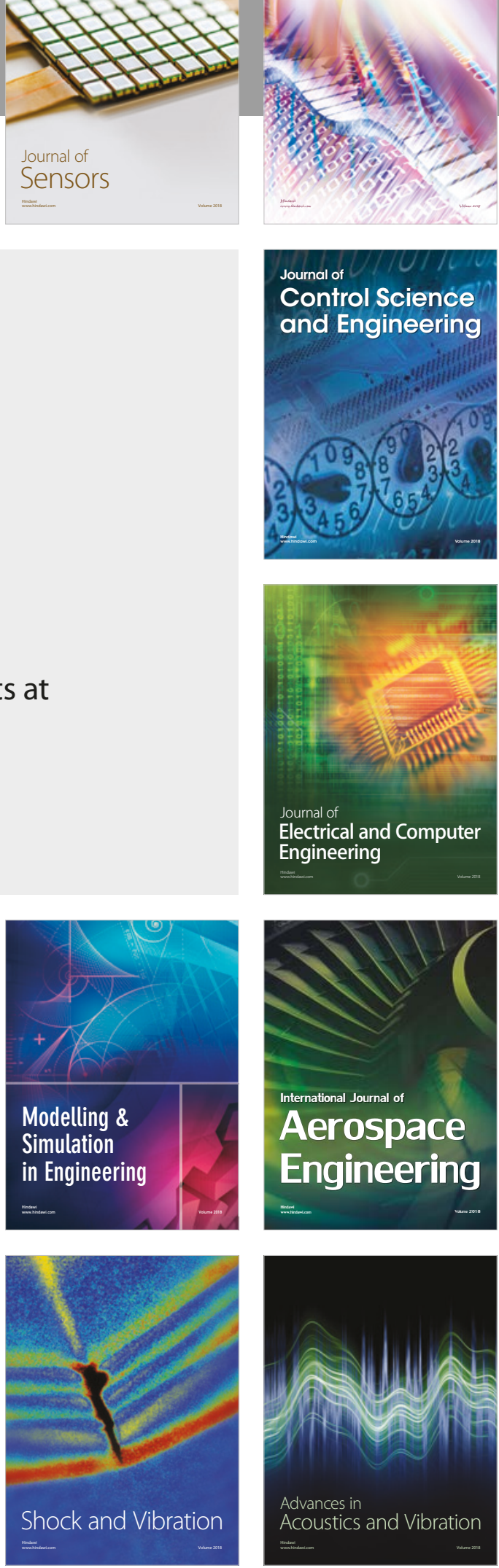